\title{
ENSINO DE MATEMÁTICA NOS ANOS INICIAIS DE ESCOLARIZAÇÃO: PRODUÇÃO DIVULGADA NO BOLETIM DE EDUCAÇÃO MATEMÁTICA (BOLEMA)
}

\author{
Thaís de Sá Gomes Novaes, Jéssica Aparecida Dutra Carvalho \\ Universidade Estadual do Norte do Paraná - UENP/CCP, Colegiado de Pedagogia, Cornélio Procópio, PR. E-mail: \\ thaisdesa@bs2.com.br.
}

\begin{abstract}
RESUMO
A pesquisa apresenta, analisa e discute uma revisão bibliográfica dos artigos sobre educação matemática publicados no periódico nacional BOLEMA (Boletim de Educação Matemática), no período compreendido entre 2007 e 2016. O objetivo do trabalho foi de investigar as pesquisas sobre o ensino de matemática nos anos iniciais de escolarização, a fim de organizar um panorama de estudos e construir um banco de dados para acesso, com intuito de auxiliar demais pesquisas sobre a temática. Foram encontrados apenas sete (07) artigos, de um total de 472, que referem-se à organização do ensino de matemática nos anos iniciais de escolarização, a partir dos referenciais da Teoria Histórico-Cultural, o que revela a necessidade de desenvolvimento de mais estudos sobre o assunto, a fim de contribuir com os docentes da Educação Básica na organização de um ensino de matemática que promova a apropriação dos conceitos científicos pelos estudantes.
\end{abstract}

PALAVRAS-CHAVE: Ensino de matemática, Teoria histórico-cultural, anos inicias.

\section{TEACHING OF MATHEMATICS IN THE EARLY YEARS OF SCHOOLING: PRODUCTION PUBLISHED IN THE MATHEMATICS EDUCATION BULLETIN (BOLEMA)}

\begin{abstract}
The research presents, analyses and discusses a review of articles about mathematics education published in the national journal BOLEMA (Mathematics Education Bulletin), in the period between 2007 and 2016. The objective of this work was to investigate the research on the teaching of mathematics in the early years of schooling, in order to organize a panorama of studies and build a database for access, in order to assist other research on the subject. Were found only seven (07) articles, of a total of 472, which refer to the organization of teaching of mathematics in the early years of schooling, from benchmarks of historical-Cultural Theory, which shows the need for development of further studies on the subject, in order to contribute with teachers of basic education in mathematics education organization that promotes the appropriation of scientific concepts by students.
\end{abstract}

KEYWORDS: Math Education, historical and cultural Theory, early years of schooling. 


\section{INTRODUÇÃO}

A matemática é uma linguagem produzida historicamente, um conjunto de signos que permite ao homem codificar e transmitir informações sobre o controle de quantidades e variações de grandezas. (MORAES,). Segundo Caraça (1989, p. XIII), a matemática "[...] aparece-nos como um organismo vivo, impregnado de condição humana, com as grandes necessidades do homem na sua luta pelo entendimento e pela libertação; aparece-nos, enfim, como um grande capítulo da vida humana social". Nesta mesma perspectiva Moura (2007, p. 44) define a matemática como um conjunto de ferramentas simbólicas criadas pelos homens para a satisfação de suas necessidades.

Sendo assim, como produto das necessidades humanas, a mesma se insere na cultura e é preciso ser socializada de maneira que contribua para a interação e desenvolvimento pleno dos indivíduos.

Nesse sentido, ao defender a necessidade de socialização dos conhecimentos matemáticos, faz-se necessário pensar o ensino da matemática em diferentes etapas da vida. No entanto, ao considerar as avaliações internacionais e nacionais, como a Provinha Brasil, Prova Brasil, Programa Internacional de avaliação de aluno (PISA), percebe-se o baixo desempenho escolar apresentado pelos alunos e consequentemente a dificuldade dos professores em organizar o ensino da matemática que promova a apropriação dos conhecimentos científicos.

Sendo assim, essa pesquisa apresenta, analisa e discute uma revisão bibliográfica dos artigos sobre educação matemática publicados no periódico nacional BOLEMA (Boletim de Educação Matemática), todos disponíveis online, no período compreendido entre 2007 e 2016 . 0 objetivo do trabalho foi de investigar as pesquisas sobre o ensino de matemática, a fim de organizar um panorama de estudos e construir um banco de dados para acesso, com intuito de auxiliar demais pesquisas sobre a temática, além de conhecer, quais pesquisas vêm sendo feitas, sobre o ensino da matemática nos anos iniciais de escolarização Tivemos, ainda, como finalidade a análise dos aspectos teóricos e metodológicos dos artigos que se fundamentavam na Teoria histórico-cultural, com o intuito de obter a tônica dos estudos no que se refere ao ensino e a aprendizagem da matemática.

\section{METODOLOGIA}

O Boletim de Educação Matemática - BOLEMA, surgiu em 1985, vinculado ao programa de Pós-graduação em Educação Matemática da UNESP de Rio Claro. Atualmente conta com conceito A1 na avaliação qualis CAPES ${ }^{1}$. Publica três edições ao ano e, eventualmente, edições temáticas, com pesquisadores convidados, de acordo com a demanda da comunidade. É constituído de trabalhos que podem ser resultados de pesquisas empíricas, ensaios, resenhas de textos, artigos convidados e resumos de teses e de dissertações defendidas na área de educação matemática.

Assim sendo, para conhecer a produção acadêmica sobre o ensino de matemática nos anos iniciais de escolarização fez-se necessário identificar os trabalhos apresentados no Boletim de Educação Matemática (BOLEMA) entre o período de 2007 a 2016; organizar o material produzido (resumos dos trabalhos) quanto à temática, conceitos da teoria abordados e tipo de estudo em um banco de dados para acesso, organização e pesquisa do material nele arrolado e; analisar a distribuição da produção acadêmica por região do país, a partir da instituição a qual pertence o(s) autor(es). Além de analisar quais conceitos da Teoria Histórico-Cultural mais aparecem nos trabalhos e também se estes vem sendo descritos de forma condizente com a Teoria HistóricoCultural.

Para a execução da pesquisa realizou-se leituras de textos específicos para fundamentação teórica, a fim de nos apropriarmos dos conceitos da escola russa para, assim, podermos analisar o

\footnotetext{
${ }^{1}$ Qualis é o conjunto de procedimentos utilizados pela Capes (Coordenação de Aperfeiçoamento de Pessoal de Nível Superior) para estratificação da qualidade da produção intelectual dos programas de pós-graduação. Como resultado, disponibiliza uma lista com a classificação dos veículos utilizados pelos programas de pós-graduação para a divulgação da sua produção.
} 
material selecionado. Realizou-se, ainda, leituras de cunho metodológico, dentre as quais destacou-se os autores Fiorentini (2002) e Justulin (2007), que realizaram estudo semelhante, com embasamento teórico nos fundamentos de Vigotski e da Teoria Histórico-Cultural; porém, com fonte e delimitação temporal diferentes do proposto aqui.

Após tais leituras, fomos até o site eletrônico http://www2.rc.unesp.br/bolema/, no qual acessamos todos os trabalhos publicados na revista entre os anos de 2007 e 2016, que totalizaram 472 artigos. Os mesmos foram salvos na extensão PDF $^{2}$ para que fosse possível realizar uma busca em cada um dos trabalhos.

No campo de busca foi utilizado o nome de Vigotski em suas três formas de escrita Vigotski, Vygotsky, Vigotsky - , a fim de identificar os trabalhos que se fundamentavam na Teoria histórico-cultural.

\section{RESULTADOS}

Dos 472 artigos publicados na delimitação temporal foram selecionados 27 artigos que, a princípio, apresentavam alguma relação com o autor e consequentemente alguns pressupostos da Teoria Histórico-Cultural.

Os 27 artigos selecionados foram analisados a partir das leituras dos títulos e resumos e classificados quanto a sua temática, conceitos da teoria abordados e tipo de estudo.

Tais informações foram organizadas em uma tabela inicial que continha os seguintes campos: título, resumo e classificação geral. Para a concretização dos objetivos propostos, fez-se necessário organizar uma tabela mais completa, na qual demonstrava os resultados de uma análise mais profunda, realizada a partir de leitura global dos artigos, na qual continha: título, autor, ano, região, tipo de estudo, temática e conceitos da Teoria histórico-cultural.

A partir da mesma tabela foi possível constatar que de todos os conceitos da Teoria histórico-cultural, os que mais aparecem são: desenvolvimento, linguagem e Zona de Desenvolvimento Proximal.

\section{DISCUSSÃO}

A partir da análise da tabela organizada, foi possível observarmos que a maioria dos trabalhos são de autores que tiveram sua formação acadêmica na região Sudeste (20), divididos entre os estados de São Paulo (16) e Minas Gerais (04). Dos demais, cinco (05) correspondem à região Sul - Santa Catarina (03) e Rio Grande do Sul (03) - e, apenas três (01) deles é de autores que se formaram no exterior, em Portugal. Encontramos, ainda, dois artigos com autores que tiveram sua formação acadêmica na Espanha e Estada Unidos. Notamos então, que em sua maioria a produção ainda concentra-se na região sudeste.

Com relação ao tipo de estudo, foi possível identificar que apenas três (03) se descrevem/classificam como parte de pesquisa de mestrado, ou seja, dissertação. Os outros artigos não fazem menção sobre o tipo de trabalho e/ou vinculação a programas.

Uma segunda análise dos 27 artigos foi realizada a fim de identificar quais dos trabalhos referiam-se ao ensino de matemática nos anos iniciais do ensino fundamental e, somente sete (07) diziam respeito aos anos iniciais do ensino fundamental.

A análise dos dados levou-nos a concluir que dos 27 artigos, apenas 18 realmente tratam da Teoria Histórico-Cultural, trazendo, de fato os pressupostos de seus autores. E, os nove (09) artigos restantes, somente citavam Vigotski sem aprofundamento teórico e, muitas vezes de modo descontextualizado.

\footnotetext{
${ }^{2}$ A sigla inglesa PDF significa Portable Document Format (Formato Portátil de Documento), isto é, um formato de arquivo criado pela empresa Adobe Systems para que qualquer documento seja visualizado, independentemente de qual tenha sido o programa que o originou. 
No que se refere à análise dos conceitos da Teoria Histórico-Cultural foi possível perceber que, em sua maioria, os conceitos que mais aparecem são: conceitos científicos, Zona de Desenvolvimento Proximal, linguagem e desenvolvimento.

A partir desses conceitos, foi identificado quais obras de Vigotski constavam nas referências desses artigos, dentre as quais "Pensamento e Linguagem", "A Formação Social da Mente" e "A construção do Pensamento e da Linguagem" foram as mais referenciadas.

\section{CONCLUSÃO}

Dentre as pesquisas que visam elaborar o estado da arte da Educação Matemática em anais de eventos e/ou periódicos, podemos citar o estudo de Fiorentini (2002), no qual o autor buscou descrever, analisar e discutir problemas e tendências temáticas e teórico-metodológicos relativos aos trabalhos do GT de Educação Matemática, num período de 4 anos, desde a sua constituição enquanto grupo de estudos até o ano de 2001, quando foi consolidado como GT-19 da ANPED. Já o trabalho de Ardenghi e Igliori (2006) teve como objetivo inventariar, sistematizar e avaliar a produção científica sobre o tema em programas de pós-graduação do Brasil, de 1970 a 2005. As fontes de pesquisa foram: artigos dos periódicos internacionais considerados mais importantes pela área da Educação Matemática (JUSTULIN et al, 2007).

Justulin et al (2007) fizeram um levantamento das produções em Educação Matemática publicadas em periódicos nacionais e anais de congresso no período de 2000 a 2007. Para tanto, realizaram a leitura de resumos das produções científicas contidas nos anais dos seguintes eventos: EBRAPEM, ENEM e SIPEM; e dos periódicos: BOLEMA, Educação Matemática em Revista e ZETETIKÉ, no período de 2000 a 2007.

Nesse sentido, a pesquisa realizada e descrita em tela mostrou-se pertinente por propor um levantamento das pesquisas sobre o ensino de matemática nos anos iniciais de escolarização no Boletim de Educação Matemática (BOLEMA), tendo como finalidade organizar um panorama dos estudos, além de constituir um banco de dados para acesso, organização e pesquisa do material para subsidiar novos estudos sobre a temática.

Foram encontrados apenas sete (07) artigos, de um total de 472, que referem-se à organização do ensino de matemática nos anos iniciais de escolarização, a partir dos referenciais da Teoria Histórico-Cultural, o que revela a necessidade de desenvolvimento de mais estudos sobre o assunto, a fim de contribuir com os docentes da Educação Básica na organização de um ensino de matemática que promova a apropriação dos conceitos científicos pelos estudantes.

\section{REFERÊNCIAS}

ARDENGHI, Marcos José; IGLIORI, Sonia Barbosa Camargo. Ensino-aprendizagem de Funções: um panorama de pesquisas realizadas sobre o tema no período de 1970 a 2005. In: Atas... Encontro Brasileiro de Estudantes de Pós-Graduação em Educação Matemática, EBRAPEM, X, Minas Gerais, 2006.

CARAÇA, Bento de Jesus. Conceitos fundamentais de matemática. 9. ed. Lisboa: Livraria Sá da Costa, 1989.

FIORENTINI, Dario. Mapeamento de balanço dos trabalhos do GT-19 (Educação matemática) no período de 1998 a 2001. Disponível em: <http://www.anped.org.br/25/te25.htm>. Acesso em: 30/03/2014.

JUSTULIN, Andressa. Maria et al. Pesquisas em educação matemática no Brasil: análise de resumos em anais de congressos e periódicos de 2000 a 2007. In: VI ENPEC - Encontro Nacional de Pesquisa em Educação em Ciências. Florianópolis : Gráfica Floriprint, 2007. v. 01. 
MORAES, Silvia Pereira Gonzaga de. A apropriação da linguagem matemática nos primeiros anos de escolarização. In: SHELBAUER, Analete Regina; LUCAS, Maria Angélica Olivo Francisco; FAUSTINO, Rosangela Célia. (Orgs.). Práticas Pedagógicas: alfabetização e letramento. Maringá: Eduem, 2010. p. 97-110.

MOURA, Manoel Oriosvaldo de. Matemática na infância. In: MIGUEIS, M. R. e AZEVEDO, M. G. Educação Matemática na infância: abordagens e desafios. Serzedo - Vila Nova de Gaia: Gailivro, 2007. p. 39-64. 